\title{
Myoid Hamartoma of Breast - A Rare Mesenchymal Lesion
}

\author{
Elizabeth Joseph ${ }^{1}$, Dahlia Joseph ${ }^{1 *}$, Blessy Mary Thomas ${ }^{1}$ and Jaison Verghese Joy ${ }^{2}$ \\ 'Dept of Pathology, Believer's Church Medical College Hospital \\ ${ }^{2}$ Dept of Surgery, Believer's Church Medical College Hospital
}

\begin{abstract}
Hamartoma is a local malformation resulting from faulty development in an organ. It was first described in breast in 1971 by Arrigoni et al and its occurrence in breast is very rare. This tumor is composed of breast lobules admixed with fibrous tissue and fibroadipose tissue. Myoid hamartoma, also called as muscular hamartoma, is composed of smooth muscle cells in addition to ducts, lobules, and stroma. Here, we report a case of myoid hamartoma which occurred in a 53year old lady with a lump in the right breast.
\end{abstract}

Keywords: Hamartoma, Breast, Myoid Hamartoma, Smooth Muscle

\section{Introduction}

Myoid hamartoma of the breast is a very rare benign lesion about which only a few cases have been reported. This rare form of breast hamartoma, accounting for $0.04-1.15 \%$ of cases, usually presents as a painless lump. Its pathogenesis was unknown until recently in a study done by Ioannis et al ${ }^{[1]}$ on genetic characterization of myoid hamartoma which may be pathogenetically related to benign connective tissue tumors with HMGA2 rearrangements, such as pulmonary hamartomas, lipomas, myolipomas, and leiomyomas. Morphologically its composed of varying proportions of differentiated mammary glandular and stromal structure, fatty tissue and smooth muscle tissue ${ }^{[2]}$. Due to its benign and atypical nature, myoid hamatoma of breast can be easily missed or misdiagnosed during routine clinical examination. As hamartoma has the potential to progress to breast cancer ${ }^{[3]}$, surgical removal is the curative treatment for breast hamartomas ${ }^{[4]}$. Herein, we present another case of this rare entity.

\section{Case Report}

A 53-year-old lady presented with a lump in the upper inner quadrant of right breast of 5 years duration. There was no history of pain or discharge from nipple. The physical examination showed a $10 \times 10 \mathrm{~cm}$ sized mobile lump. There was no lymphadenopathy. Ultrasound showed a large welldefined heterogeneously iso to hypoechoic lesion $(8.8 \mathrm{x}$ $5 \mathrm{~cm}$ ) in the central upper periareolar region of right breast at 10 to 2'o'clock position. Few small cystic areas noted within. No calcification /internal vascularity detected. The axillary tail region and bilateral axillae appear normal. Mammogram showed large well-defined homogeneously hyperdense lesion in the central quadrant of right breast.
Trucut biopsy from the lesion showed only fibromuscular tissue fragments. Later excision biopsy of the lesion was done and sent for histopathological examination. The postoperative period was uneventful.

The specimen measuring $11 \times 10 \times 5 \mathrm{~cm}$. Cut surface showed well circumscribed lesion $8 \times 5 \mathrm{cms}$ having faintly lobulated appearance with tiny cystic spaces and myxoid change. Microscopically, the lesion was composed of fibrous tissue, smooth muscle fibers and adipose tissue [Fig 1 and 2]. In addition, dilated ducts showing columnar cell change and few acini were noted. Immunohistochemistry showed positivity for Desmin [Fig 3] and smooth muscle actin (SMA)[Fig 4]. The morphological and immunohistochemistry findings were consistent with a diagnosis of myoid hamartoma.

\section{Discussion}

Hamartoma is an uncommon breast tumor that accounts for approximately $4.8 \%$ of all benign breast masses ${ }^{[5]}$. It is a tumour composed of lobular breast tissue with fibrous, fibrocystic and adipose tissue. The diagnosis of hamartoma in breast is rare and the pathogenesis is poorly understood. The term myoid hamartoma is used when the tumour shows a significant smooth muscle component and the term was first used by Davies and Riddeil in 1973 [6].

The pathogenesis is unclear and they are thought to be due to dysgenesis rather than a true tumorous process [7]. The origin of smooth muscle in myoid hamartoma is not that clear. It could be from the blood vessels, nipple or undifferentiated breast stromal tissue or myoepithelial cells, or metaplasia of breast stromal cells into smooth muscle cells. The role of female sex hormones has also been described ${ }^{[8]}$. 


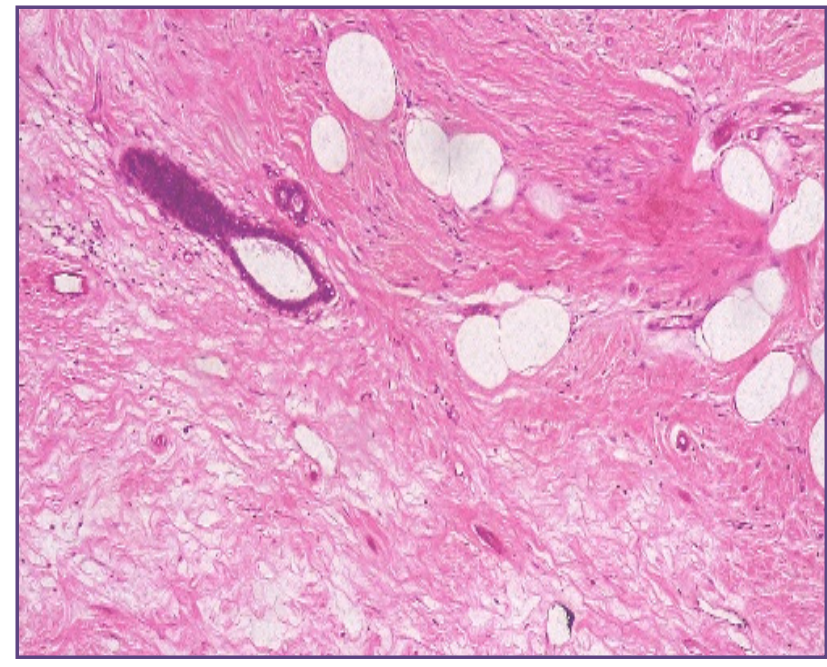

Fig. 1: Breast tissue with fat and smooth muscle, H\&E, 200X.

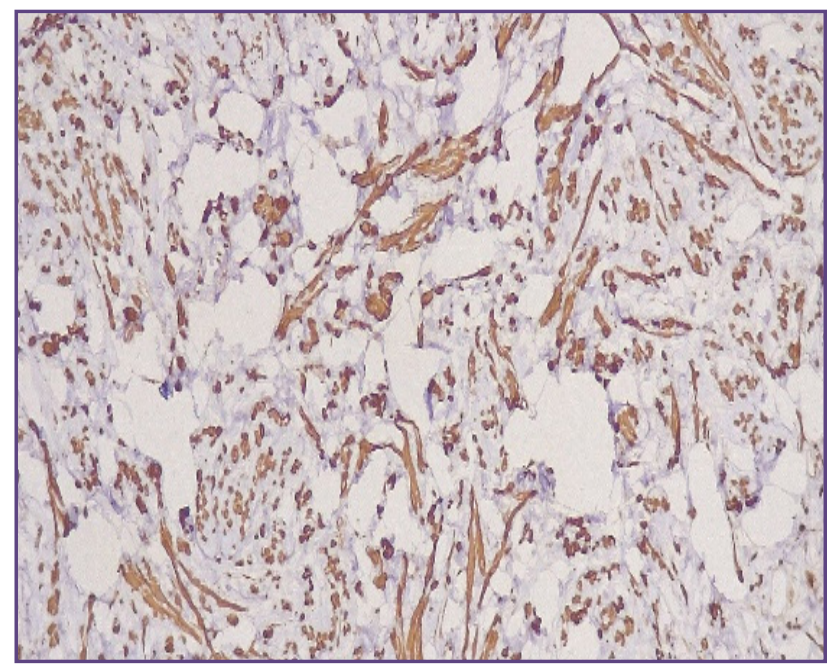

Fig. 3: IHC - Desmin.

The review of literature showed predominantly case reports and the largest review was that reported by Sevim et al in $2014{ }^{[7]}$, where they described 27cases of breast hamartoma, one among them being myoid hamartoma. Charpin et al ${ }^{[5]}$ reported 41 cases. The average age of the patients ranged between 33.5 and 66.5 years.

The incidence of hamartoma may increase in future due to the advancement in radiological techniques. The typical mammographic appearance shows radiolucent lesions with fat, fibrous and adenomatous tissue with smooth rim and a thin capsule ${ }^{[9]}$

Hamartoma exhibit diverse pathological features like sclerosis, pseudoangiomatous stroma. Malignancies associated with breast hamartomas are rarely reported.

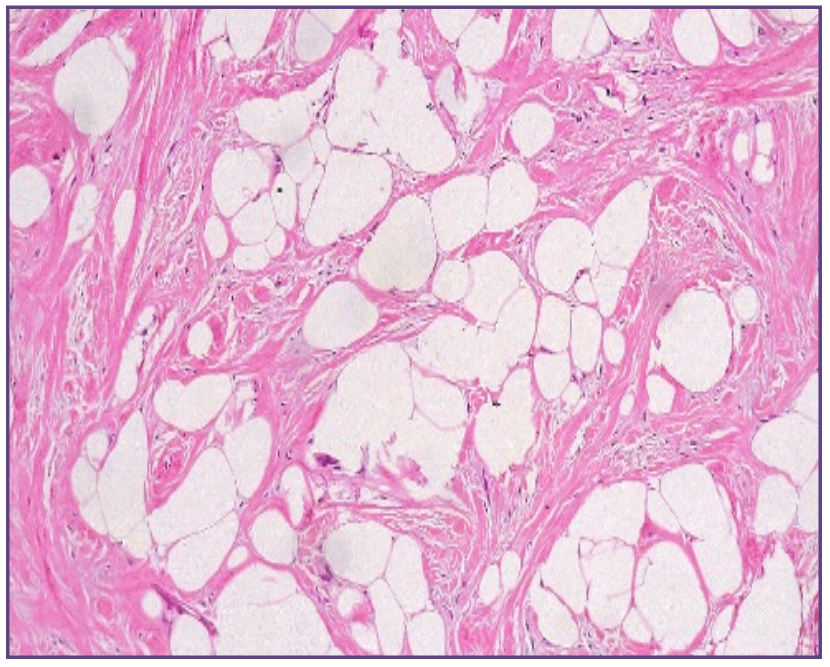

Fig. 2: Fat \& smooth muscle tissue, H\&E 400x.

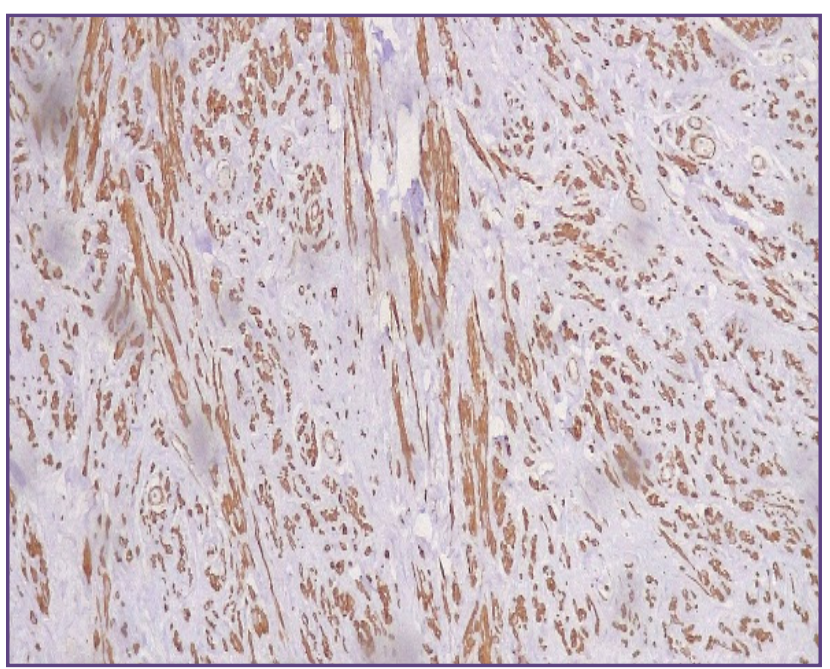

Fig: 4. IHC - Smooth Muscle Actin (SMA).

Occurrence of Invasive carcinoma, LCIS as well as epithelial hyperplasia are described in literature ${ }^{[10] .}$

Immunohistochemically, SMA [Fig 4], Desmin [Fig 3] and Vimentin ${ }^{[1]}$ are positive in these lesions, and the same was found in the present study.

\section{Conclusion}

The occurrence of myoid hamartoma in breast is a rarity. Clinically, it can mimic fibroadenoma and histopathological examination is the definitive mode of diagnosis in these cases.

\section{Acknowledgements}

We sincerely thank the department of surgery for providing the details of the case and staff of the department of pathology for their technical support. 


\section{Funding}

NA

\section{Competing Interests}

NIL

\section{References}

1. Panagopoulos I, Gorunova L, Andersen HK, Pedersen TD, Lømo J, Lund-Iversen M, Micci F, Heim S. Genetic Characterization of Myoid Hamartoma of the Breast. Cancer Genomics Proteomics. 2019 Nov-Dec;16(6):563-568.

2. Tian Xia, Chunmei Qin, Hanan Long, Tiejun Zhou , Xiuli Xiao. Mammary myoid hamartomas: reports of two cases and a review of the literature. Int J Clin Exp Pathol 2019;12(7):2398-2404.

3. Mester J, Simmons RM, Vazquez MF and Rosenblatt R: In situ and infiltrating ductal carcinoma arising in a breast hamartoma. AJR Am J Roentgenol. 175:64-66. 2000.

4. Guray $M$ and Sahin AA: Benign breast diseases: classification, diagnosis and management. Oncologist. 11:435-449. 2006.
5. Charpin C, Mathoulin MP, Andrac L, Barberis J, Boulat J, Sarradour B, et al. Reappraisal of breast hamartomas. A morphological study of 41 cases. Pathol Res Pract. 1994;190(4):362-7

6. Davies JD, Riddell RH. Muscular hamartomas of the breast. J Pathol. 1973;111(3):209-11.

7. Sevim Y, Kocaay AF, Eker T, Celasin H, Karabork A, Erden E, et al. Breast hamartoma: a clinicopathologic analysis of 27 cases and a literature review. Clinics. 2014;69(8):515-523.

8. Tse GM, Law BK, Ma TK, Chan AB, Pang LM, Chu WC, et al. Hamartoma of the breast: a clinicopathological review. J Clin Pathol. 2002;55(12):951-4

9. Altermatt HJ, Gebbers JO, Laissue JA. Multiple hamartomas of the breast. Appl Pathol. 1989;7(2):145-8.

10. Wahner-Roedler DL, Sebo TJ, Gisvold JJ. Hamartomas of the breast: clinical, radiologic, and pathologic manifestations. Breast J. 2001;7(2):101-5.

11. Mizuta N, Sakaguchi K, Mizuta M, Imai A, Nakatsukasa K, Morita M, et al. Myoid hamartoma of the breast that proved difficult to diagnose: a case report. World J Surg Oncol. 2012;10:12.

*Corresponding author:

Dr. Dahlia Joseph, Dept of Pathology, Believer's Church Medical College Hospital

Phone: +91 8281827283

Email: drdahliajoseph@gmail.com

Date of Submission $\quad: \quad 22 / 02 / 2021$

Date of Final Revision : 17/04/2021

Financial or other Competing Interests: None.

Date of Acceptance $\quad: \quad 16 / 05 / 2021$

Date of Publication : $\quad 30 / 05 / 2021$ 